
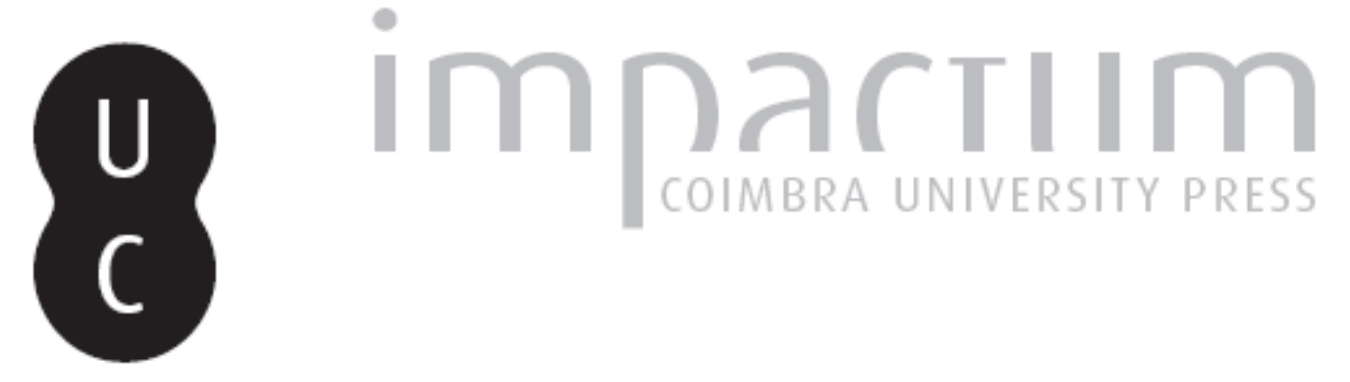

\title{
A diversidade e os media na obra de Godfrey Reggio
}

Autor(es): $\quad$ Pinto, Alexandra Lima Gonçalves

Publicado por: Imprensa da Universidade de Coimbra

URL persistente:

URI:http://hdl.handle.net/10316.2/43232

DOI:

DOI:https://doi.org/10.14195/2183-5462_31_10

Accessed : $\quad$ 26-Apr-2023 03:44:53

A navegação consulta e descarregamento dos títulos inseridos nas Bibliotecas Digitais UC Digitalis, UC Pombalina e UC Impactum, pressupõem a aceitação plena e sem reservas dos Termos e Condições de Uso destas Bibliotecas Digitais, disponíveis em https://digitalis.uc.pt/pt-pt/termos.

Conforme exposto nos referidos Termos e Condições de Uso, o descarregamento de títulos de acesso restrito requer uma licença válida de autorização devendo o utilizador aceder ao(s) documento(s) a partir de um endereço de IP da instituição detentora da supramencionada licença.

Ao utilizador é apenas permitido o descarregamento para uso pessoal, pelo que o emprego do(s) título(s) descarregado(s) para outro fim, designadamente comercial, carece de autorização do respetivo autor ou editor da obra.

Na medida em que todas as obras da UC Digitalis se encontram protegidas pelo Código do Direito de Autor e Direitos Conexos e demais legislação aplicável, toda a cópia, parcial ou total, deste documento, nos casos em que é legalmente admitida, deverá conter ou fazer-se acompanhar por este aviso.

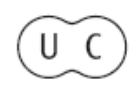




\section{Media Jornalismo}

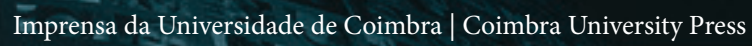

N. 31 Vol. 17, N. ${ }^{\circ} 2$ - 2017

Esia

(2) M MEDIA E DIVERSIDADE

लिखिएक

2)

*).

() (6) $3(9)$

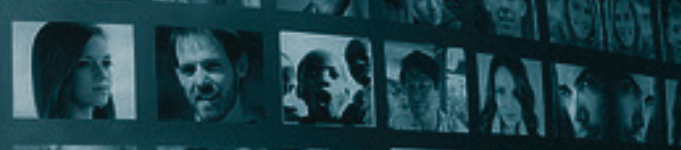

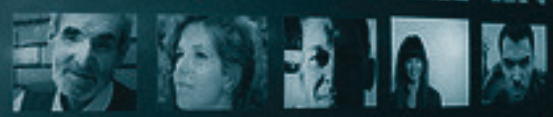

* a

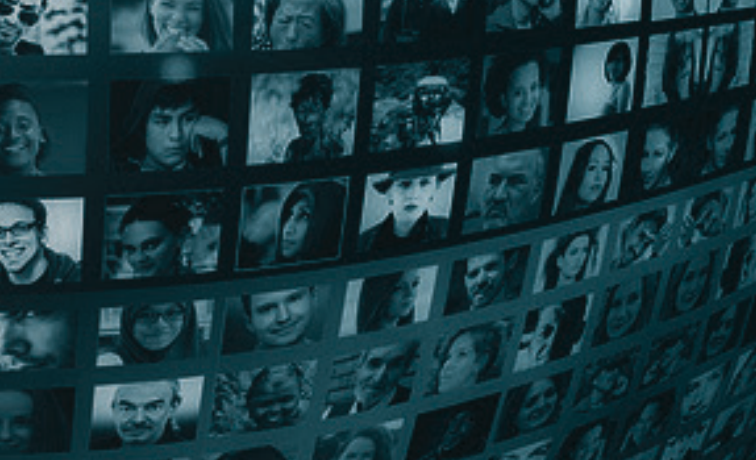

तथ 


\title{
A DIVERSIDADE E OS MEDIA NA OBRA DE GODFREY REGGIO
}

\section{DIVERSITY AND MEDIA IN THE WORK OF GODFREY REGGIO}

\author{
ALEXANDRA LIMA GONÇALVES PINTO \\ Universidade Federal de São Carlos (UFSCAR), Brasil \\ CIC.Digital (FCSH/NOVA) \\ alexandralimagpinto@gmail.com
}

\section{Resumo}

Este texto aborda a obra audiovisual de Godfrey Reggio, realizador independente norte-americano que tem a Tecnologia como seu tema principal. Ao longo de sua obra, marcada por um olhar poético e filosófico, Reggio produziu uma crítica contundente do mundo tecnológico contemporâneo. Seus filmes expõem o conflito entre a Natureza e a Tecnologia, vista pelo realizador como uma nova natureza, artificial; mais do que algo que utilizamos, ele considera que a Tecnologia é o meio ambiente no qual vivemos hoje. Apesar do paradoxo de utilizar o audiovisual para criticar a Tecnologia, Reggio o faz de uma forma consciente e criativa. Um estudo mais profundo sobre seus filmes e as suas principais influências e referências teóricas nos leva a questionar a homogeinização tecnológica reinante e a perguntar se a diversidade é realmente possível nos media.

\section{Palavras-chave:}

Tecnologia; Media; Cinema e Televisão; Diversidade; Homogenização cultural

\section{ABstract}

This text approaches the work of Godfrey Reggio, independent American director who has Technology as his main theme. Throughout his work, marked by a poetic and philosophical look, Reggio produced a striking critique of the contemporary world. His films expose the conflict between Nature and Technology, seen by the filmmaker as a "new nature", artificial. More than anything we use, he believes that Technology is the environment in which we live today. Despite the paradox of using the audiovisual to criticize Technology, Reggio does so in a conscious and creative way. A deeper study of his films and their main influences and theoretical references leads us to question the prevailing technological homogenization and to ask whether diversity is actually possible in the media.

KEYWORDS:

Technology; Media; Cinema and Television; Diversity; Cultural Homogenization

INTRODUÇÃO

A paisagem imponente do deserto norte-americano ergue-se com toda a beleza e a majestade de seus canyons, não como pano de fundo de algum faroeste como 
de costume mas para ser protagonista de um filme diferente: "Koyaanisqatsi", um documentário experimental, não verbal, feito apenas com imagens e música - sem nenhuma narração, depoimento ou entrevista - embora ancorado na força dessa palavra indígena que, na língua, significa "vida fora de equilíbrio".

As imagens da natureza que abrem o filme logo são sucedidas pelas explosões do lançamento de um foguete e, posteriormente, dos testes nucleares que foram realizados no deserto, onde por muito tempo viveram os Hopi ou "Povo da Paz", como se auto-denomina a população original desse território, que hoje pertence aos Estados Unidos da América. A natureza exuberante dessa região, com suas formações rochosas e rios, dá lugar à fumaça preta das máquinas. Entra em cena a Tecnologia e com ela as cidades, os automóveis, o métro, as usinas, os aviões... e os media.

Uma das raras realizações independentes que conseguiu chegar ao circuito cinematográfico internacional, esse filme, que inicia a trilogia "Oatsi" ("Vida”, em Hopi), estreou nos cinemas mundiais em 1983. Com uma linguagem poética e inovadora, que dá forma ao olhar filosófico de seu realizador, Godfrey Reggio, "Koyaanisqatsi" é um alerta sobre a ameaça da tecnologia e dos media à diversidade ecológica e cultural do planeta. Assim como os outros dois filmes que se seguiram a ele, "Powaqqatsi" (1988) e "Naqoyqatsi" (2002), o primeiro filme da trilogia critica a sociedade tecnológica e a destruição desencadeada por ela. Godfrey Reggio enfatiza o papel dos media nesse processo, não apenas na trilogia Qatsi mas também em outros filmes que realizou, nomeadamente em "Evidence (of children watching television)" (1995) e em "Visitors" (2013), que ele considera como um "réquiem".

Nascido em 1940, nos Estados Unidos, Godfrey Reggio nunca frequentou uma escola de cinema nem tinha ambição de construir uma carreira na área. Boa parte de sua juventude, dos quatorze aos vinte e oito anos, foi passada em um mosteiro cristão, onde dedicou-se à oração, meditação e serviço. Sua trajetória pessoal foi fortemente marcada pelo trabalho que desenvolveu com gangues de rua em Santa Fé, no Novo México. Foi nessa época que teve a oportunidade de assistir e exibir para os meninos com quem trabalhava o filme "Los Olvidados" (1950) de Luis Buñuel, que o fez perceber o poder do cinema de tocar profundamente a si mesmo e aos demais. Diante das pressões da Igreja Católica para que ele interrompesse sua ação educativa com esses garotos e fosse trabalhar nos Arquivos do Vaticano, em Roma, Godfrey Reggio decidiu abandonar a vida religiosa e se engajar em um trabalho de media independente, marcado pelo ativismo social, que teve início com a realização de uma campanha patrocinada pela União Americana pelas Liberdades Civis, no início dos anos setenta, que tinha como objetivo informar a população sobre a invasão de privacidade e o controle do comportamento das pessoas por meio da tecnologia.

A respeito do mundo contemporâneo, retratado em seus filmes, o realizador afirma que "nós fomos incorporados em um ambiente artificial que veio substituir a natureza. Nós não vivemos mais coma natureza; vivemos acima dela, olhamos para ela como recurso para manter esse ambiente artificial funcionando" (MacDonald, 1992: 389). De acordo com Reggio, para quem a Tecnologia, "com T maiúsculo", é o foco principal dos seus filmes, o "mito da neutralidade" - a ideia de que a tecnologia é neutra e de que é o seu uso que determina o seu valor - é totalmente inadequado. 
"A tecnologia moderna nos separou completamente da natureza ao ponto de que hoje a tecnologia é a nossa nova natureza - ao invés de 'anima mundi', é 'techno mundi'. 0 mistério se foi com a certeza dos princípios tecnológicos. Então o verdadeiro terror, a verdadeira agressão contra a vida, vem na forma da nossa busca de uma felicidade tecnológica. (...) A paz, a justiça e o equilíbrio ambiental são consequências do nosso comportamento, não apenas das nossas intenções. A meu ver é ingênuo rezar pela paz mundial, se não mudamos a forma em que vivemos" (Clyne, 2003: 3)

Consciente do paradoxo de utilizar um meio tecnológico como o cinema para criticar a tecnologia e os seus efeitos sobre a humanidade e o planeta, Godfrey Reggio afirma, no entanto, que "se você quer falar com alguém você tem que usar a sua língua e a língua franca do nosso mundo hoje é a imagem, a tecnologia" (MasterClass com o realizador durante o Escenarios Festival Documental, no México, em 2009).

Em seus filmes, a presença da tecnologia e dos mediaé vista de uma forma bastante crítica, que enfatiza o seu impacto negativo. 0 olhar de Godfrey Reggio permite enxergar as distorções e os problemas gerados por uma cultura hipertecnológica; no entanto, se o seu pessimismo radical tem um papel importante ao questionar a realidade atual, por outro lado é fundamental não perder de vista a complexidade da questão para evitar incorrer em uma abordagem maniqueísta.

Para isso, é preciso compreender não apenas os seus filmes em si - uma vez que eles são obras artísticas, que permitem mais de uma interpretação, em especial por não terem falas - como também as ideias dos principais autores que 0 influenciaram, como o filósofo e sociólogo francês Jacques Ellul, entre outras referências teóricas importantes que são nominalmente citadas por ele, seja nos créditos finais de "Koyaanisqatsi" ou em suas diversas entrevistas e depoimentos.

\section{UM OLHAR FILOSÓFICO SOBRE A SOCIEDADE CONTEMPORÂNEA}

Jacques Ellul foi um dos poucos pensadores do século XX que ousaram questionar e investigar a sociedade tecnológica, em seus mais diversos aspectos. Originalmente Ellul não usou o termo "tecnologia" e sim "técnica" (algo que seria alterado a partir da reedição americana de seu livro mais famoso, "La technique ou l'enjeu du siècle", de 1954, que passou então a se chamar "The technological society", em 1964). Ellul preferia utilizar o termo "técnica" por ser mais amplo do que "tecnologia", tendo em vista que não queria restringir sua análise sobre ela a alguns dispositivos particulares - em geral, "máquinas" - pois entendia a técnica, antes de mais nada, como um conjunto de métodos racionalmente desenvolvidos e que visam à eficiência em determinados contextos.

Ao longo de sua obra, composta de 23 livros sobre esse tema, Ellul questionou como a técnica - e/ou a tecnologia - influencia os seres humanos em vários campos como a política, a arte, as classes sociais e até mesmo a possibilidade ou não de uma revolução. Para ele, esse é o elemento central da civilização moderna e não o capital, embora reconheça que exista uma fusão muito dinâmica e intensa entre ambos. Como afirma Gregory Wagenfuhr sobre a visão desse teórico:

"Ellul apresenta uma metanarrativa ambiental ao investigar três épocas que ele denomina de 'pré-histórica', 'histórica' e 'pós histórica'. Essas três eras são 
cada uma delas caracterizadas pela dominância de um certo tipo de fator ambiental: a natureza, a sociedade e a técnica, respectivamente. (...) Todos os fatores na vida são mediados através do meio ambiente. (...) A narrativa de Ellul começa com a pré história na qual o meio ambiente da humanidade era a natureza. A sociedade e a técnica existiam simultaneamente, mas elas eram submetidas e mediadas pela natureza. Com o estabelecimento das cidades, o advento da agricultura e a emergência do período neolítico, a humanidade entrou num meio ambiente social onde natureza e técnica eram mediados pela sociedade. Finalmente e mais importante, Ellul considera que a humanidade se moveu do meio ambiente social para o meio ambiente técnico através do qual a natureza e a sociedade são mediadas. Essa entrada no meio ambiente técnico, é então a avaliação de Ellul da situação humana contemporânea, encontrada na maior parte dos seus trabalhos. As técnicas humanas não são um fenômeno novo para Ellul, o que é radicalmente novo e diferente é o seu papel na mediação e finalmente na formação do material bruto da experiência humana" (Wagenfuhr, 2013: 231).

0 pensamento de Jacques Ellul tem uma influência fundamental na obra de Godfrey Reggio, juntamente com as ideias de seu amigo e mentor, Ivan Illich (que assim como Ellul, foi um dos pioneiros a reenquadrar a tecnologia em uma problemática filosófica, moral e ética), entre outros autores. Mas sem dúvida foi a cosmovisão dos índios Hopi que Ihe deu a confirmação da validade da sua própria visão do mundo em que vivia. Em uma entrevista, Reggio narra o que lhe disse David Monongya, líder Hopi, um homem extremamente vital embora contasse na época com quase noventa anos, no primeiro encontro que tiveram: "Tudo que vocês brancos chamam de 'normal' nós chamamos de 'anormal'. Tudo que vocês chamam de 'são' nós chamamos de 'insano'." Reggio diz que foi liberador ouvir isso porque "não podia entender a insanidade do mundo, a falta de preocupação. (...) Simplesmente não podia entender nossa desumanidade uns com os outros." (Whitaker, 2006: 4).

A escolha de palavras nessa língua indígena para os títulos dos filmes da trilogia não é fortuita. Reggio queria trazer o estranhamento dos Hopi perante a sociedade contemporânea. Através de seus filmes é possível enxergar aspectos muitas vezes "invisíveis" desse mundo, a despeito de estarem bastante evidentes (ou exatamente por isso, como afirma o realizador). 0 principal deles é a homogeinização tecnológica reinante, sobre a qual Reggio declarou durante uma de suas entrevistas:

"Os novos media estão produzindo uma enorme unidade no mundo. E mais do que nunca, essa unidade é mantida através da homogeneização técnica. Na verdade, não usamos mais tecnologia. Nós vivemos isso. A tecnologia torna-se o modo de vida, que é o foco quintessencial de nosso assunto nesta trilogia. Na ordem natural, que eu acho que agora está subsumida na ordem pós-natural, a unidade da ordem natural é mantida através do mistério ou da teia da diversidade. Essa diversidade está sendo eliminada em detrimento da homogeneização tecnológica. Assim, o milagre que testemunhamos através da internet, através da globalização, através da informatização da linguagem, da cultura, de todos os aspectos de nossa existência, vem ao preço da diversidade global". (Herman, 2015: 7). 
Essa tendência da tecnologia de se expandir geograficamente, absorvendo todos os países, pessoas e civilizações pode ser vista em "Powaqqatsi", o segundo filme da trilogia que Reggio realizou e que em Hopi significa "um modo de viver que consome a força vital de outros seres para prolongar a própria vida". Nesse filme, Reggio mostra como as diversas culturas do planeta foram sendo transformadas pela chegada da industrialização, da tecnologia e dos media, em especial da televisão e da publicidade. A padronização da televisão fica especialmente clara nesse filme quando aparecem imagens de propagandas e programas jornalísticos realizados em países diferentes mas com uma mesma linguagem, um único formato que se repete a despeito dos diferentes locais de produção. As diferenças culturais, ressaltadas no mosaico visual da primeira metade do filme, que é composto de imagens dos mais diversos povos (foram captadas imagens em treze países, incluindo o Peru, Brasil, Quênia, Egito, Nepal, Índia, China, etc.), são apagadas pela entrada das imagens televisivas, bem como pela transformação das paisagens históricas que ocorre com a incorporação da tecnologia e dos modos de vida ocidentais.

"Koyaanisqatsi" e "Powaqqatsi", foram lançados na década de oitenta (em 1983 e 1988, respectivamente). Já o terceiro filme da trilogia, "Naqoyqatsi" ("vida como guerra"), foi lançado quase duas décadas depois do início da trilogia "Oatsi", em 2002. Embora tenha em comum com os outros dois filmes o fato de também ser composto apenas de imagens e música, como todos os filmes do realizador, ele é bem diferente dos dois primeiros pois é feito basicamente com imagens de arquivo, que foram manipuladas e combinadas com imagens geradas por computador e por instrumentos técnico-científicos. 0 resultado final é que nesse último filme da trilogia "Oatsi" já não há nenhuma distinção entre o mundo real e o virtual, 0 que é bastante significativo, tendo em vista que o filme retrata o estado das coisas do modo de vida atual, globalizado, no qual a tecnologia digital está a se tornar onipresente e as imagens técnicas transformam-se cada vez mais na própria paisagem.

Para além da trilogia "Oatsi", a crítica de Reggio à tecnologia e aos media - sobretudo a televisão - está presente em outros filmes, como "Evidence" e "Visitors".

"Evidence (of children watching television)", realizado em 1995, critica de forma simples e contundente a relação das crianças com a televisão ao permitir que 0 espectador simplesmente veja as suas reações enquanto elas vêem TV, observe os seus olhares e os seus gestos. Através disso, o filme fornece uma "evidência" de como a televisão afeta as crianças, independente do seu conteúdo, segundo Reggio.

"Visitors", seu último filme até agora, lançado em 2013, retoma a proposta de "Evidence" e a aplica a pessoas de diferentes faixas etárias, em sua relação com diversos media. É um filme lento e contemplativo, com planos longos e imagens em preto e branco e infra-vermelho onde pode-se observar demoradamente as pessoas enquanto assistem TV ou jogam games, os seus rostos e suas expressões - ou em muitos casos, a ausência delas, o que causa um estranhamento no espectador.

Esse estranhamento é especialmente reforçado quando esses rostos são contrapostos ao rosto vivaz de uma gorila que, com seus gestos e olhares, parece questionar o que está ocorrendo com os humanos. Depois, vêem-se mãos que manipulam instrumentos invisíveis mas facilmente identificáveis, como ratos de computador e telas sensíveis ao toque. Essas imagens, dos rostos e das mãos humanas, surgem 
entremeadas a cenas de espaços urbanos em ruínas, imagens da natureza em infra-vermelho e da superfície sem vida da lua.

Em uma declaração quanto à sua visão sobre a tecnologia e a intenção que está presente nos filmes que realizou, Godfrey Reggio afirma que:

"A tecnologia é poder e controle; tecnologia é nosso destino. E os humanos oferecem rebelião contra o destino como uma forma de alcançar a liberdade. Jacques Ellul, o filósofo francês, dizia que o nosso maior ato de liberdade é conhecer 0 que determina o nosso comportamento. Ivan Illich, outro grande filósofo, dizia que a liberdade é a habilidade de dizer 'não' à necessidade tecnológica. 'Visitors' e os filmes que eu fiz tentam buscar a escuridão a partir dessa luz ofuscante e opressiva da tecnologia. Eu acredito no valor positivo de dizer 'não'. Há um valor positivo da revolução, se ela é real. Essas ações são percebidas pela ordem estabelecida como negativas e é essa mesma negatividade que produz algo positivo. É através da rebelião contra o destino - uma negação do destino - que algo de positivo ou esperançoso acontece. (Malkin, 2014:17)"

\section{Media e diversidade}

Numa das sequências de "Koyaanisqatsi", que acompanha a aceleração dos veículos e das pessoas nas ruas, dos carrinhos de compras nos supermercados, das esteiras de produção nas fábricas, a velocidade é intensificada ainda mais pela inserção de imagens televisivas em zapping e finalmente culmina com a explosão dos aparelhos de TV. Essa cena remete à obra de Jerry Mander, autor de "Quatro argumentos para a eliminação da televisão", com quem Reggio travou um intenso diálogo, desde a época da produção de seu primeiro filme, que durou sete anos.

Tanto Reggio como Mander tiveram um contato direto com o povo Hopi e com outros povos indígenas norte-americanos. Reggio inclusive pediu - e obteve - autorização dos anciãos Hopi para poder nomear os filmes de sua trilogia com palavras nesse idioma. Por outro lado, algumas das conclusões a que Mander chegou sobre os efeitos nefastos da televisão vieram da experiência que ele teve com os Hopi bem como da observação da relação dos media - e em especial, da televisão - com eles e com outros povos indígenas, como descreve em seu livro dedicado ao tema.

Ambos realizam uma crítica da tecnologia e dos "dispositivos tecnológicos de mediação simbólica ou media, como são comumente designados" (Esteves, 2015: 101) e em especial da televisão embora Reggio tenha feito isso "usando o fogo para lutar contra o fogo", isto é, através da própria tecnologia audiovisual. Essa crítica está presente em quase todos os seus filmes, exceto em um deles, chamado "Anima Mundi", que é justamente uma celebração da diversidade da natureza.

Em um primeiro momento, Mander escolheu concentrar os seus argumentos apenas contra a televisão, propondo a sua total eliminação diante dos malefícios listados em sua obra, apesar de saber que isso seria algo muito improvável, mesmo que as pessoas concordassem com ele quanto aos inúmeros problemas causados por ela. Por isso mesmo, ele questiona quase ao final do livro que dedicou ao tema:

"Por que é tão impensável que possamos eliminar uma tecnologia inteira? Se os argumentos das páginas precedentes são mesmo que parcialmente corretos, 
então a televisão produz uma tal coleção de efeitos prejudiciais - mentais, psicológicos, fisiológicos, ecológicos, económicos, políticos; efeitos que são perigosos para as pessoas e também para a sociedade e o planeta - que me parece que a única proposição lógica é a de que esse meio nunca deveria ter sido introduzido ou que, uma vez introduzido, não se deveria permitir sua continuidade"(Mander, 1975: 254).

Godfrey Reggio e Jerry Mander compartilham de um mesmo ponto de vista de que a tecnologia e os media destróem a diversidade. Mander considera que a televisão, em especial, por sua própria natureza, é perigosa tanto para a saúde das pessoas como para o meio ambiente e os processos democráticos. Ele afirma que os problemas da televisão "são inerentes à tecnologia em si" (Mander, 1977: 259) e não tem como ser solucionados pois mesmo quando há uma aparente diversidade na televisão, ela é esmagada pela homogeneização pois "esse meio não pode lidar com a ambiguidade, sutileza e a diversidade" (Mander, 1977: 240).

Em seu livro sobre (e contra) a televisão, ele observa que:

"(...)os comentaristas de notícias negros e asiáticos, assim como as mulheres, são inseparáveis em tom de voz, fraseado, atitudes, estilo de roupas, comportamento em geral e aparente perspectiva política das centenas de homens brancos que os precederam nesses papéis. A cor e o sexo são mais variados agora mas a mensagem é a mesma. (...) Na medida em que pessoas mais diversificadas ocupam o controle central dos sistemas, os sistemas não se tornam mais diversos. As pessoas perdem sua diversidade e começam a ser transformadas pelos sistemas. Os sistemas permanecem os mesmos. Os padrões perceptivos que foram excluídos continuam excluídos. Se alternativas ao estilo de vida dos sistemas existem, elas não são representadas." (Mander, 1975: 250-251)

0 meio ambiente técnico que reina no mundo atual e que se estende aos mais diversos campos e atividades, é caracterizado por um "colonialismo tecnológico", no qual "a diversidade de crenças e narrativas não representa uma característica de uma humanidade nova e livre mas ironicamente de uma humanidade radicalmente integrada", segundo Gregory Wagenfuhr (2013). Segundo esse autor:

"0 colonialismo nacionalista está praticamente morto, enquanto o colonialismo tecnológico, corporativo e até caridoso e paternalista vive e prospera. É irônico que num mundo que se congratula pela diversidade de suas pequenas narrativas exista uma crença sagrada subliminar a prioriem uma definição 'do que significa ser humano' que necessita da 'evangelização' dos 'selvagens' com o 'evangelho' da medicina moderna, das franquias de comida americana e do direito humano de acesso à internet. Essa atitude colonial é um aspeto necessário não apenas para legitimar uma visão de mundo específica, mas também pela boa intenção de civilizar o selvagem. (...) Aqueles que não existem no ambiente técnico não existem ainda como seres humanos plenos, e há uma acusação moral contra nós SE nós o chamamos humanos e não provemos a eles com os meios necessários para serem humanos. Isso nada mais é do que mascarar o colonialismo técnico por trás dos mitos de justiça e igualdade". (Wagenfuhr, 2013: 237) 
Para Jacques Ellul, a diversidade promovida pela técnica é uma diversidade aparente, superficial, pois "duas culturas, das quais uma é a técnica, não podem coexistir" (Ellul, 1964: 130). 0 meio ambiente técnico/tecnológico pode produzir uma variedade de pequenas narrativas que dão a sensação de uma aparente diversidade social mas isso, na verdade, é algo falso e potencialmente perigoso pois mascara ainda mais a homogeinização gerada por eles, que Reggio chama de "tecnofascismo".

"(...) Celebrar a diversidade social não é celebrar a liberdade de escolha humana tanto quanto é mascarar a crescente uniformidade global necessitada pelas leis da técnica. Identidades nacionais, religiosas, raciais e de gênero estão se tornando progressivamente mais superficiais na medida em que uma pessoa de qualquer origem, credo ou gênero pode operar um computador com uma performance equivalente. Pessoas de diferentes culturas e linguagens usam os mesmos dispositivos que utilizam a mesma linguagem interna e especializada para mediar atividades básicas da vida. Essa uniformidade linguística evidencia a ascensão de um ambiente novo e cada vez mais uniforme" (Wagenfuhr, 2013: 238).

Para Jerry Mander, "as pessoas que usam a televisão se tornam mais parecidas umas com as outras, índios que aprendem televisão não são mais índios". (Mander, 1975: 260). 0 autor é categórico ao afirmar que os media e em especial a televisão são incapazes de retratar essas culturas em profundidade, devido a limitações do próprio meio e da linguagem que ela convencionalmente utiliza.

A obra de Reggio, assim como a dos autores que 0 influenciaram ou com os quais ele dialoga, como é o caso de Mander, exigem um estudo e uma reflexão aprofundada. A despeito de sua postura evidentemente tecnófoba não se pode simplesmente descartar suas ideias pois elas apresentam aspectos extremamente relevantes para refletir não apenas sobre a televisão como também sobre os media e a tecnologia de um modo geral. Evidentemente é necessário questionar algumas colocações de Mander, como a sua proposta de "eliminar" a TV, contrapondo-as com a visão de outros autores sobre o tema. Entre eles está Arlindo Machado, que aborda a questão do "repertório" na televisão, enfatizando a sua diversidade possível e exemplificando-a através de várias experiências artísticas realizadas na televisão.

"Na minha opinião, a televisão é e será o que fizermos dela. Nem ela nem qualquer outro meio, estão predestinados a ser qualquer coisa fixa. Ao decidir o que vamos ver ou fazer na televisão, ao eleger as experiências que vão merecer a nossa atenção e o nosso esforço de interpretação, ao discutir, apoiar ou rejeitar determinadas políticas de comunicação, estamos, na verdade, contribuindo para a construção de um conceito e uma prática de televisão." (Machado, 2005: 12).

Sua visão sobre a televisão pode ser estendida para os outros media, como ele mesmo observa, destacando que "o que esse meio é ou deixa de ser não é, portanto, uma questão indiferente às nossas atitudes com relação a ele" (Machado, 2015: 12).

A própria obra de Godfrey Reggio pode ser vista como um exemplo de como a atitude pode modificar os media, no caso, o cinema, ainda que, antes de se dedicar a ele, o realizador tenha produzido também alguns spots para a televisão, os quais 
foram realizados dentro da campanha mediática que desenvolveu no início dos anos setenta e que está na origem de seus filmes. Tais spots, porém, também se destacaram da linguagem convencional da televisão, por serem enigmáticos, o que levava os espectadores a telefonarem às emissoras para perguntarem a respeito deles, 0 que colaborou para a repercussão e o sucesso da campanha.

Posteriormente, nos seus filmes, ele optou por trazer ao "primeiro plano" aquilo que normalmente estava relegado ao "plano de fundo": as paisagens, urbanas e naturais, que normalmente são apenas cenários para histórias fictícias ou mesmo documentais. Ao eliminar a narração e as falas, utilizando-se exclusivamente da música e das imagens, ele também desafiou algumas regras dos documentários mais convencionais, negando-se a dar um sentido único para as cenas, cuja leitura deste modo permanece mais ambígua, apesar da articulação realizada pela montagem.

Seu trabalho pertence a um "modo visual mais complexo", classificado por Bill Nichols como o "modo poético" do documentário (Nichols, 2016: 160), o qual situa-se em uma estilística fílmica que se encontra na intersecção do documentário com o experimental e é marcado por um "desejo expressivo de dar novas formas e perspectivas ao mundo representado" (Nichols, 2016: 218).

E importante ressaltar, no entanto, que a diversidade é vista como uma característica do próprio documentário, de maneira geral, pois "ele nunca foi uma coisa só" (Nichols, 2016: 42), sempre foi marcado por uma pluralidade de olhares e de vozes. 0 próprio termo, "considerado inapropriado e no entanto, incontornável" (Gauthier, 2011: 17), é bastante questionado pois existem diversas definições do que seria um documentário.

"(...) Podemos usar essa história de um sentido cambiante sobre o que se considera documentário como sinal da qualidade dinâmica aberta e variável do modelo. (...) A diversidade dos filmes que compõem a tradição do documentário também contribui para a sua fluidez. Embora diferentes, Nanook, o esquimó, 0 Homem da Câmera (1929), Terra sem pão, Basquete Blues, A caminho do leste (1967), Koyaanisqatsi (1983) e Roger e Eu são todos marcos da produção de documentários. Todos adotam e modificam convenções associadas ao documentário. Oferecem maneiras alternativas de ver 0 mundo (...)." (Nichols, 2016: 42-43).

No caso de Reggio, a utilização de recursos tecnológicos inovadores na época do lançamento dos seus primeiros filmes, como a aceleração e a desaceleração das imagens através de time lapse e high speed photography, bem como a manipulação digital em seus últimos trabalhos, trouxe um caráter ainda mais experimental e revolucionário à sua obra, do ponto de vista não apenas temático mas de linguagem.

Por tudo isso, a obra de Godfrey Reggio pode considerada como um exemplo concreto de diversidade no cinema, tendo sido muito copiada posteriormente em termos da sua linguagem, mas não de sua visão crítica.

\section{Comentário Final}

A obra cinematográfica de Godfrey Reggio indaga, de forma radical, até que ponto a diversidade é realmente possível nos media e na sociedade mediática/tecnológica ou não. Seus filmes são especialmente importantes por abordar essa questão 
de uma forma ampla, dando-lhe um sentido que vai além da dimensão social e cultural humana, envolvendo também a natureza e os outros animais, não humanos, isto é, a diversidade da Vida como um todo.

Para além do risco de pensar essa dicotomia em termos de "bem" e "mal", existe uma diferença essencial entre natureza e tecnologia que precisa ser melhor percebida. Esta compreensão é fundamental para que se possa estabelecer uma relação mais equilibrada entre ambas na sociedade contemporânea, em especial neste momento, marcado por inúmeros desafios ambientais e sociais que foram gerados justamente por um grande desequilíbrio entre esses dois campos. Nessa perspectiva, pode-se afirmar que uma "outra história é possível, diferente daquela da tecnicização, da inserção do homem no mundo técnico: uma história que não é mais mecânica e necessária mas que ao contrário, está para ser inventada e que não se completa em catástrofe." (Ellul, 1987: 246)

Como já apontava o título do primeiro filme de Godfrey Reggio, "Koyaanisqatsi" - palavra que na língua Hopi permite mais de uma leitura - trata-se não apenas de uma forma de vida "em perturbação", que está "desintegrando" ou "fora de equilíbrio", mas sobretudo de "vida que pede uma nova forma de viver".

\section{REFERÊNCIAS BIBLIOGRÁFICAS}

Aitken, I. (2013). The concise Routledge Encyclopedia of the Documentary Film. London: Routledge.

Clyne, C. (2003). A Wordless view of life. Satyamagazine. Agosto 2003. http://satyamag. com/live/back-issues/2003-2/aug03/satya-aug-03-interview-with-godfreyreggio/. Acedido em 08/07/2016.

Dempsey, M. (1989) Qatsi means life: the films of Godfrey Reggio. Film Quarterly 42 (3).

Ellul, J. (1964) The technological society. New York: Vintage Books.

Esteves, J. P. (2015). A linguagem perante o desafio dos media: novas gramáticas da vida quotidiana e a reconfiguração das identidades sociais. In Cádima, F. R. e Sáàgua, J. Comunicação e Linguagem: Novas convergências. Lisboa: UNL.

Gauthier, G. (2011) 0 documentário: um outro cinema. Campinas: Papirus.

Greenman, J. (2012) Understanding Jacques Ellul. Eugene: Wipf and Stock Publishers.

Herman, J. (2011). Godfrey Reggio's Life out of balance. Arts Journal. October 27, 2011. http:// www.artsjournal.com/herman/2011/10/godfrey_reggio.html Acedido em 09/09/2016.

Machado, A. (2005). A televisão levada a sério. São Paulo: Senac.

MacDonald, S. (1992). A Critical Cinema 2. Interview with independent filmmakers. Berkeley: University of California Press.

MacDonald, S. (2015). Avant-Docs - Intersections of Documentary \& Avant Garde Cinema. New York: Oxford University Press.

Malkin, J. (2014). The Computer is the new divine: Visitors director Godfrey Reggio on man versus machine. Good Times. September 24, 2014. http://goodtimes.sc/cover-stories/ reflecting-glass/. Acedido em 06/07/2016.

Mander, J. (1978). Four Arguments for the elimination of television. New York: Harper Perennial. Mander, J. (1991). In the Absence of the Sacred: The failure of Technology and the survival of indian nations. New York: Random House. 
Mander, J. (2007) Paradigm Wars - Indigenous Peoples Resistance to Globalization. Berkeley: University of California Press.

Nichols, B. (2016) Introdução ao documentário. Campinas: Papirus.

Shaw, J. (2014). Illusions of Freedom: Thomas Merton and Jacques ellul on Technology and the Human Condition. Eugene: Wipf and Stock Publishers.

Toly, S.; Greenman (2012). Understanding Jacques Ellul. Eugene: Wipf and Stock Publishers. Wangenfuhr, G. (2013) Postmodernity, the phenomenal mistake: sacred, myth and environment. In Jeronimo, H.M. et al. (eds). Jacques Ellul and the technological society in the 21st century. Dordrectht: Springer Media.

Whitaker, Richard (2006) Godfrey Reggio: A Call for another way of living. Works and Conversations - Interviews and Articles. February 18, 2006. http://www.conversations.org/ story.php?sid=91. Acedido em 10/07/2016.

Alexandra Gonçalves Pinto - Professora do Departamento de Artes e Comunicação da Universidade Federal de São Carlos (UFSCar), no Brasil. Doutoranda do curso de Ciências da Comunicação da FCSH/NOVA. Investigadora colaboradora do CIC.Digital (Pólo FCSH/NOVA)

Artigo por convite /Article by invitation 